\title{
PREVALÊNCIA DE ALTERAÇÃO NO FRÊNULO LINGUAL E SUAS IMPLICAÇÕES NA FALA DE ESCOLARES
}

\author{
Prevalence of change in frenulun lingual and its implications \\ in speech of school children
}

\author{
Lívia Augusta dos Santos Braga (1), Jozi da Silva (2), \\ Camila Leal Pantuzzo ${ }^{(3)}$, Andréa Rodrigues Motta ${ }^{(4)}$
}

\begin{abstract}
RESUMO
Objetivos: verificar a prevalência do frênulo lingual alterado e suas implicações na fala de escolares. Métodos: foram avaliados por três fonoaudiólogas os frênulos de língua de 260 crianças com idades variando entre 6 e 12 anos. Os frênulos foram classificados por meio de inspeção visual, medidas empregando-se paquímetro e avaliação da tensão, mobilidade e posicionamento da língua. Foram consideradas crianças com alteração de frênulo aquelas que apresentaram alteração em todas etapas da avaliação. Nos casos de classificação de frênulo alterado, a fala foi avaliada. Resultados: os dados encontrados revelaram que das 260 crianças avaliadas 47 (18\%), apresentaram alteração de frênulo, sendo 28 (60\%), classificados como curtos; 12 (25\%) como anteriorizados e 7 (15\%) como curtos e anteriorizados. Não houve diferença entre os sexos. Dos indivíduos com frênulo alterado, 34 (72 \%) apresentaram alteração de fala. A prevalência de alteração na fala foi maior no frênulo curto e anteriorizado (85\%), seguido pelo curto $(75 \%)$ e pelo anteriorizado $(58 \%)$. As implicações de fala mais encontradas foram distorção e articulação trancada. Conclusão: foi verificada uma prevalência de $18 \%$ de alteração no frênulo lingual dentre os escolares avaliados, sem diferença entre os sexos. O frênulo curto predomina sobre os demais tipos, porém o curto e anteriorizado apresenta maiores implicações na fala. As características de fala mais comuns nestes casos são distorção e articulação trancada.
\end{abstract}

DESCRITORES: Prevalência; Língua; Freio Lingual; Doenças da Língua; Distúrbios da Fala; Fonoterapia

\section{INTRODUÇÃO}

O frênulo da língua é uma prega mediana de túnica mucosa que conecta a língua ao assoalho

(1) Fonoaudióloga da Clínica Psicopedagógica Barreiro, Belo Horizonte, MG; Especialização em Motricidade Orofacial pelo CEFAC - Pós-Graduação em Saúde e Educação.

(2) Fonoaudióloga; Clínica Jozi da Silva, Belo Horizonte, MG; Especialização em Motricidade Orofacial pelo CEFAC Pós-Graduação em Saúde e Educação.

(3) Fonoaudióloga do Asilo Nossa Senhora da Piedade, Belo Horizonte, MG; Especialização em Motricidade Orofacial pelo CEFAC - Pós-Graduação em Saúde e Educação.

(4) Fonoaudióloga; Professora Assistente do Departamento de Fonoaudiologia da Universidade Federal de Minas Gerais, UFMG, Belo Horizonte, MG; Doutoranda em Distúrbios da Comunicação Humana na Universidade Federal de São Paulo.

Conflito de interesses: inexistente da boca, permitindo a parte anterior desse órgão mover-se livremente ${ }^{1}$. Por não ser um músculo, não tem origem nem inserção ${ }^{2}$.

No recém-nascido o frênulo lingual é posicionado do ápice da língua até a base do processo mandibular alveolar. Na medida que existe desenvolvimento e crescimento ósseo, com prolongamento lingual e erupção dentária, o frênulo migra para posição central até ocupar a sua fixação definitiva com erupção dos segundos molares decíduos ${ }^{3}$.

$\mathrm{Na}$ literatura são encontradas classificações diferentes de frênulos: mucoso curto, mucoso longo de fixação mandibular e hipertrófico fixado na crista do rebordo alveolar ${ }^{4}$. O frênulo lingual pode ser classificado também como curto, com fixação anteriorizada e curto com fixação anteriorizada ${ }^{1}$.

A anquiloglossia, vulgarmente conhecida como língua-presa, é uma anomalia congênita incomum, 
mas não rara caracterizada por um freio lingual curto ${ }^{5}$ e grosso, resultando em limitações nos movimentos da língua ${ }^{6-9}$. Estudos apontam predisposição maior em meninos do que em meninas ${ }^{10-12}$.

Os fonoaudiólogos encontram muitos pacientes com queixas diversas que levam à hipótese de que o frênulo da língua pode apresentar alguma alteração, sendo o causador, ou pelo menos, agravante dos problemas verificados ${ }^{13}$. Os problemas mais comuns estão relacionados às dificuldades de articulação da fala ${ }^{3-6,9-20}$. O falante poderá apresentar limitações ao realizar movimentos articulatórios mais amplos e elaborados, o que reduz a abertura de boca ${ }^{13,15,19,21,22}$ e seus grupos consonantais ${ }^{15}$. Outros sons da fala que podem ser afetados englobam os fones [t], [d], [z], [s], [r], [tz], [l] 14,16,19,22,23 $[\lambda]^{15,22},[n]^{14,19}$. Movimentos de protrusão ${ }^{9,16}$, elevação, retrusão, lateralização ${ }^{9} \mathrm{e}$ vibração ${ }^{12,22-24}$ também se encontram prejudicados. Estas alterações, geralmente surgem na infância e se mantém na vida adulta caso não sejam tratadas.

Outra alteração citada na literatura refere-se à alimentação principalmente durante a fase de amamentação ${ }^{5,9-11,16}$. Os principais sintomas associados à anquiloglossia na amamentação são dor no mamilo da mãe ${ }^{25}$, dificuldade na ordenha e sucção, que resultam em desmame precoce e perda de peso ${ }^{11,26}$.

Devido às limitações dos movimentos da língua em decorrência de alterações no frênulo, pode-se ainda observar ineficiência dos processos de mastigação ${ }^{7,13,19}$ e deglutição ${ }^{3,7,9,13,19,23}$ especialmente no estágio oral ${ }^{27}$ (por dificuldade de acoplamento da língua no palato duro) ${ }^{13}$ devido à postura baixa de língua ${ }^{19}$, que por sua vez, gera acúmulo de alimentos na cavidade oral ${ }^{17}$. Encontrou-se também referência à interposição anterior ou bilateral de língua ${ }^{8,19}$. Ainda são citadas alterações dentárias como, por exemplo, o diastema ${ }^{28}$, alterações de oclusão e do tecido periodontal ${ }^{4,6}$. Alguns dos problemas relacionados à anquiloglossia, tais como dificuldade de lamber os lábios, sorvete, beijar ${ }^{20}$, implicam em constrangimentos sociais $5,16-18,28$.

A literatura fonoaudiológica é escassa em relação ao tema, incluindo pesquisas conclusivas quanto à existência de uma possível associação entre a presença e o grau de limitação gerada pelo frênulo encurtado e/ou com fixação anteriorizada e a quantidade ou gravidade das decorrentes distorções de fala ${ }^{24}$

Portanto, o objetivo deste estudo foi verificar a prevalência de frênulo lingual alterado e suas implicações na fala de escolares.

\section{MÉTODOS}

Foi realizado um estudo transversal, observacional e descritivo cuja amostra consistiu de 260 crianças em período escolar, na faixa etária compreendida entre 6 a 12 anos. O trabalho foi realizado em três escolas municipais localizadas na cidade de Belo Horizonte.

Foram empregados os seguintes critérios de inclusão no estudo: apresentar idade entre 6 e 12 anos, estar regularmente matriculado na escola, e assinatura por parte dos pais ou responsáveis do Termo de Consentimento Livre e Esclarecido. Foram excluídas do estudo crianças que já realizaram frenectomia lingual, fonoterapia ou que apresentaram alguma alteração física ou cognitiva que interferisse na avaliação fonoaudiológica.

Cada criança foi submetida à avaliação por três fonoaudiólogas, que realizaram previamente treinamento para calibração. A avaliação foi composta por três etapas (Figura 1). Estas foram realizadas de forma sigilosa por cada uma das avaliadoras que posteriormente revelaram o resultado de sua observação, prevalecendo apenas os dados concordantes.

$\mathrm{Na}$ primeira etapa as profissionais avaliaram o frênulo para caracterizá-lo como normal ou alterado por meio da inspeção visual, baseando-se no seguinte critério ${ }^{15}$ : a) frênulo normal: fixação vai da metade da face inferior da língua (face sublingual) até o assoalho da boca; b) frênulo curto: fixação em local correto e com tamanho pequeno; c) fixação anteriorizada: apresenta tamanho adequado e fixase em qualquer ponto na face inferior da língua, do meio para a frente ou próximo ao ápice, o que dificulta e/ou impede a elevação do terço anterior; d) curto com fixação anteriorizada: apresenta tamanho menor com fixação à frente da metade da face inferior da língua, ou seja, este frênulo é misto dos dois anteriores.

$\mathrm{Na}$ segunda etapa foram tomadas duas medidas com o uso do paquímetro digital Digimess Stainless Steel: a) Máxima distância interincisal; b) Máxima distância interincisal com língua na papila. Para realização da primeira medida a criança foi solicitada a abrir a boca ao máximo, e em seguida colocar o ápice de sua língua na papila palatina para mensuração da segunda medida. $\mathrm{O}$ instrumento foi higienizado com detergente $\mathrm{e}$ álcool $70 \%$ a cada utilização. Após a coleta das medidas com o paquímetro, foi aplicada regra de três relacionando a abertura máxima de boca sem e com a língua na papila, no qual o valor da segunda medida foi multiplicado por 100 e dividido pelo valor obtido na primeira medida. De acordo com a porcentagem obtida o resultado menor que $50 \%$ indicou frênulo alterado, entre $51 \%$ e $59 \%$ alterado ou normal e maior que $60 \%$ normal ${ }^{13}$. 


\section{PROTOCOLO DE AVALIAÇÃO}

Data: _ I _ _

Nome:

Idade: anos e meses Data de nascimento:

Escola

\section{Fixação do frênulo}

\section{A - No assoalho da boca}

$\square$ fixação na crista alveolar inferior $\square$ fixação entre as carúnculas sublinguais (ductos submandibulares) Inserção em outro ponto:

$\mathrm{B}$ - Na face inferior da língua (face sublingual)

$\square$ a fixação está no meio da face inferior da língua $\square$ a fixação está à frente do meio da língua

$\square$ a fixação está quase na ponta da língua

\section{Classificação do Frênulo:}

a Normal

Alterado: $\square$ Curto $\square$ Anteriorizado $\square$ Curto e anteriorizado

\section{Medidas realizadas com o paquímetro}

Abertura de boca (máxima distância interincisal):

\begin{tabular}{|c|c|c|}
\hline Medida I (em $\mathrm{mm})$ & Medida II $(\mathrm{em} \mathrm{mm})$ & Média (em $\mathrm{mm})$ \\
\hline & & \\
\hline
\end{tabular}

Abertura de boca (máxima distância interincisal com língua na papila):

\begin{tabular}{|l|l|l|}
\hline Medida I $(\mathrm{em} \mathrm{mm})$ & Medida II $(\mathrm{em} \mathrm{mm})$ & Média $(\mathrm{em} \mathrm{mm})$ \\
\hline & & \\
\hline
\end{tabular}

\section{Fotografia}

Foto frênulo: $\square \operatorname{Sim} \square$ Não

\section{Língua}

Tensão: $\square$ Adequada $\square$ Levemente hipotensa $\square$ Hipotensa $\square$ Hipertensa

\section{Posicionamento da língua durante} postura habitual

$\square$ no assoalho da boca

$\square$ entre os dentes

$\square$ com as laterais aparecendo

não se vê

\section{Praxias}

Para fora e para dentro: $\square$ Normal $\square$ Alterado $\square$ Ausente Para cima: $\square$ Normal $\square$ Alterado $\square$ Ausente Para baixo: $\square$ Normal $\square$ Alterado $\square$ Ausente Para lado direito: $\square$ Normal $\square$ Alterado $\square$ Ausente Para lado esquerdo: $\square$ Normal $\square$ Alterado $\square$ Ausente Estalo de ponta de língua: $\square$ Normal $\square$ Alterado $\square$ Ausente Sucção: $\square$ Normal $\square$ Alterado $\square$ Ausente Vibração: $\square$ Normal $\square$ Alterado $\square$ Ausente Ao elevar a língua o assoalho da boca vem junto? 口 sim a não

Ao protrair a ponta fica retangular ou quadrada

$\square \operatorname{sim} \square$ não

\begin{tabular}{|l|c|c|}
\hline 5.Fala & Sim & Não \\
\hline Ceceio anterior & & \\
\hline Ceceio lateral & & \\
\hline A (s) lateral(is) da língua durante a fala aparece $(\mathrm{m})$ & & \\
\hline A fala, como um todo, é imprecisa & & \\
\hline A fala é produzida com a boca mais fechada & & \\
\hline Fala mais rápido do que o comum das pessoas & & \\
\hline
\end{tabular}

Nomeação (ABFW)

Transcrição: 
As crianças que apresentaram frênulo normal na inspeção visual e, concomitantemente, nas medidas realizadas com o paquímetro foram excluídas da amostra. Assim, foram para a terceira etapa, as crianças que apresentaram alteração na primeira e segunda etapa.

$\mathrm{Na}$ terceira etapa as crianças foram fotografadas com a câmera fotográfica Kodak modelo EasyShares Cx7430, e posteriormente submetidas à avaliação funcional, que abrangeu aspectos como tensão da língua, posicionamento da mesma durante a postura habitual, praxias, observação do assoalho da língua durante a elevação e o formato retangular/quadrado ou em forma de coração do ápice ao protuir a língua.

Para a avaliação da tensão lingual as crianças foram solicitadas a empurrar a língua contra uma espátula. Nesta avaliação, os critérios considerados, de acordo com a capacidade da língua imprimir força e mantê-la, foram: adequada, levemente hipotensa, hipotensa ou hipertensa ${ }^{29}$. Em relação às praxias as crianças foram solicitadas a realizar movimentos com a língua para verificação de liberdade de movimentos da mesma. Os movimentos solicitados foram: língua para fora, dentro, cima, baixo, lado direito, lado esquerdo, estalo de ponta de língua, sucção e vibração.

Ao final da avaliação, foram consideradas crianças com comprometimento no frênulo aquelas que apresentaram alteração em todas as etapas descritas acima, isto é, na inspeção visual (primeira etapa), nas medidas realizadas com o paquímetro (segunda etapa), e em alguma prova da avaliação funcional (terceira etapa).

As crianças que, nas três etapas, apresentaram de alteração no frênulo lingual tiveram a fala avaliada.

Para esta verificação as crianças foram submetidas à prova de nomeação da parte de fonologia do teste de linguagem infantil ABFW, que verificou o inventário fonético da criança bem como as regras fonológicas usadas, com o propósito de verificar as possíveis implicações da fala decorrentes do frênulo alterado. O teste aplicado foi filmado com a camêra Kodak modelo EasyShares Cx7430, a fim de facilitar a coleta de dados e auxiliar posteriormente a análise.

Foram empregados os seguintes materiais no presente estudo: protocolo de avaliação, luvas de látex descartável, abaixador de língua de plástico, álcool 70\%, gaze, detergente, paquímetro digital Digimess Stainless Steel, câmera fotográfica Kodak modelo EasyShares Cx7430.
As avaliações foram realizadas com cada criança individualmente, na própria escola, em local silencioso e privado. As crianças que apresentaram alterações importantes na avaliação foram encaminhadas para serviços especializados para buscar tratamento adequado.

A presente pesquisa foi avaliada e aprovada pelo Comitê de Ética em Pesquisa do CEFAC Pós-graduação em Saúde e Educação, sob nº 009/08, sendo considerada sem risco e com necessidade de Consentimento Livre e Esclarecido.

Os resultados foram submetidos à análise estatística apropriada, considerando-se um nível de significância de 5\%, sendo aplicados na análise os testes estatísticos de Qui-quadrado e Exato de Fisher.

\section{RESULTADOS}

A amostra foi composta por 260 crianças de 6 a 12 anos de idade com média de $8,4 \pm 1,5$ anos. Ao considerar apenas as crianças que apresentaram alteração em todas as etapas da avaliação, o frênulo foi classificado como curto em 28 participantes (60\%), anteriorizado em $12(25 \%)$ e curto e anteriorizado em sete (15\%), totalizando 47 (18\%) escolares com alteração. Comparando-se o sexo com esta última classificação não foram observadas diferenças significantes entre meninos e meninas (Figura 2).

Foi comparada a distribuição da amostra em relação à classificação e fixação do frênulo no assoalho da boca, na qual foi verificada diferença significante entre os grupos, conforme apresentado na Tabela 1.

$\mathrm{Na}$ Tabela 2 as categorias frênulo anteriorizado, curto e curto e anteriorizado foram avaliadas duas a duas em relação à presença ou não de alteração na tensão, posicionamento, presença de elevação do assoalho e aspecto da ponta da língua. Desta forma, observou-se que indivíduos que apresentaram frênulo curto, curto e anteriorizado, têm maior prevalência de ponta de língua quadrada do que aqueles que apresentam frênulo anteriorizado.

A Figura 3 refere somente os tipos de praxias que apresentaram maiores alterações (vibração, sucção, estalo e língua para cima). Não houve correlação entre os tipos de frênulo e praxias, porém nota-se que o frênulo curto e anteriorizado apresentou maior alteração nas praxias para cima e vibração. A praxia de sucção demostrou alterada nos frênulos curto e curto e anteriorizado. 


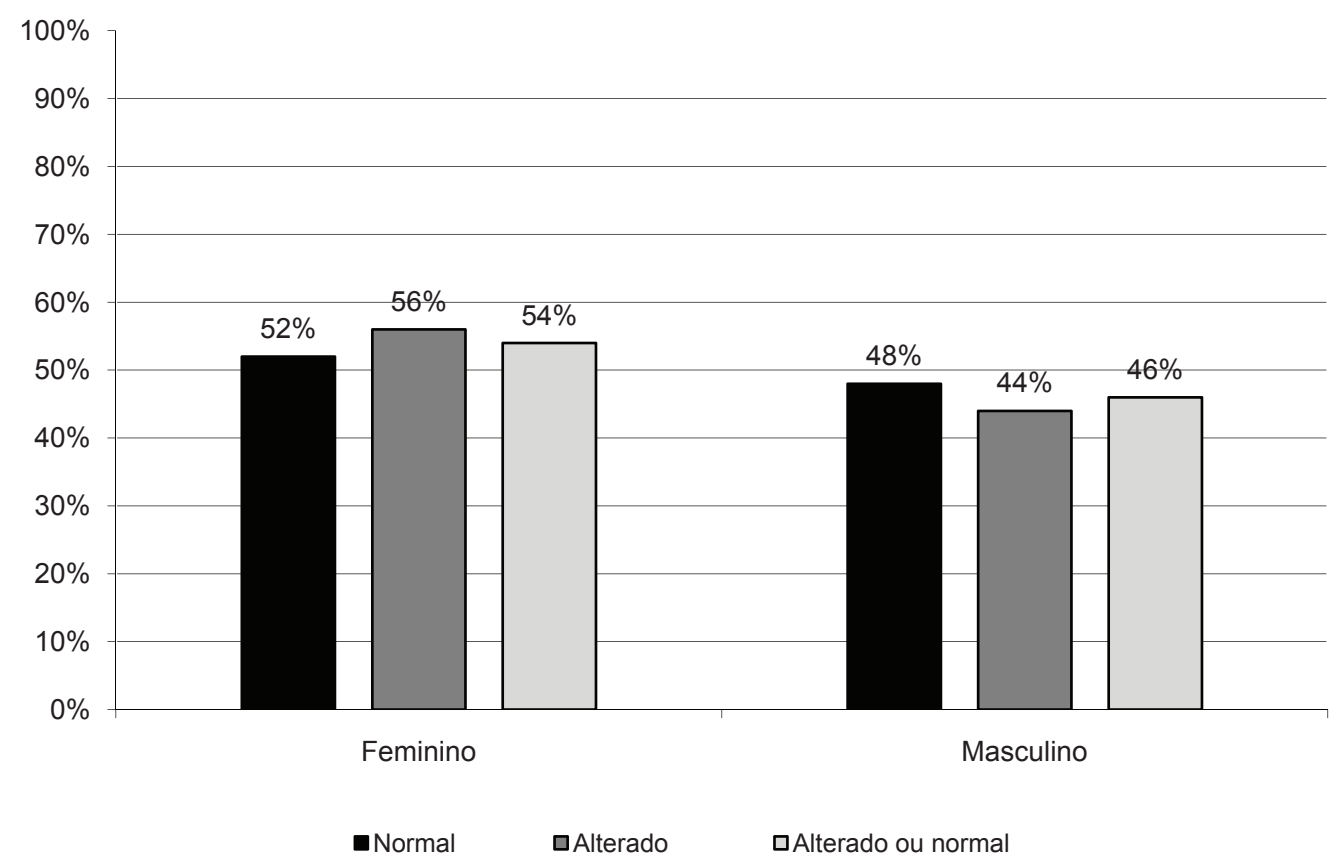

Teste Qui-Quadrado: $\mathrm{p}$-valor=0,8940

Figura 2 - Distribuição da amostra quanto à presença de alteração no frênulo lingual e sexo (N=47)

Tabela 1 - Distribuição da amostra total em relação à classificação e fixação do frênulo lingual ( $\mathrm{N}=260)$

\begin{tabular}{|c|c|c|c|c|c|c|c|}
\hline \multirow[b]{3}{*}{ Classificação } & \multicolumn{7}{|c|}{ Fixação } \\
\hline & \multicolumn{3}{|c|}{ Assoalho da boca } & \multicolumn{4}{|c|}{ Face lingual } \\
\hline & $\begin{array}{l}\text { Crista } \\
\text { alveolar }\end{array}$ & $\begin{array}{l}\text { Carúncula } \\
\text { Sublingual }\end{array}$ & p-valor* & $\begin{array}{l}\text { A frente do } \\
\text { meio da língua }\end{array}$ & $\begin{array}{l}\text { Meio da face } \\
\text { inferior da } \\
\text { língua }\end{array}$ & $\begin{array}{l}\text { Quase ponta } \\
\text { da língua }\end{array}$ & p-valor* \\
\hline \multirow{2}{*}{ Normal } & 110 & 103 & & 54 & 152 & 7 & \\
\hline & $(74 \%)$ & $(93 \%)$ & & $(82 \%)$ & $(86 \%)$ & $(39 \%)$ & \\
\hline \multirow{2}{*}{ Curto } & 21 & 7 & & 4 & 22 & 2 & \\
\hline & $(14 \%)$ & $(6 \%)$ & & $(6 \%)$ & $(12 \%)$ & $(11 \%)$ & \\
\hline \multirow{2}{*}{ Anteriorizado } & 12 & 0 & & 5 & 1 & 6 & \\
\hline & $(8 \%)$ & $(0 \%)$ & & $(8 \%)$ & $(0,75 \%)$ & $(33 \%)$ & \\
\hline \multirow{2}{*}{$\begin{array}{l}\text { Curto e } \\
\text { anteriorizado }\end{array}$} & 6 & 1 & & 3 & 1 & 3 & \\
\hline & $(4 \%)$ & $(1 \%)$ & & $(4 \%)$ & $(0,75 \%)$ & $(17 \%)$ & \\
\hline \multirow{2}{*}{ Total alterados } & 39 & 8 & 0,0005 & 12 & 24 & 11 & 0,0001 \\
\hline & $(26 \%)$ & $(7 \%)$ & & $(18 \%)$ & $(14 \%)$ & $(61 \%)$ & \\
\hline \multirow{2}{*}{ Total Geral } & 149 & 111 & & 66 & 176 & 18 & \\
\hline & $(100 \%)$ & $(100 \%)$ & & $(100 \%)$ & $(100 \%)$ & $(100 \%)$ & \\
\hline
\end{tabular}

* Teste Qui-Quadrado 
Tabela 2 - Classificação do frênulo dentre as crianças com alteração de acordo com tensão, posicionamento de língua e características anatômicas $(\mathrm{N}=47)$

\begin{tabular}{|c|c|c|c|c|c|c|}
\hline Classificação & & $\begin{array}{c}\text { Tensão } \\
\text { adequada }\end{array}$ & $\begin{array}{l}\text { Posição } \\
\text { normal }\end{array}$ & $\begin{array}{l}\text { Elevação do } \\
\text { assoalho }\end{array}$ & $\begin{array}{c}\text { Ponta } \\
\text { retangular ou } \\
\text { quadrada }\end{array}$ & $\begin{array}{c}\text { Ponta em } \\
\text { coração }\end{array}$ \\
\hline \multirow{6}{*}{ Anteriorizado } & \multirow{2}{*}{ Sim } & 2 & 3 & 8 & 1 & 5 \\
\hline & & $(17 \%)$ & $(25 \%)$ & $(67 \%)$ & $(8 \%)$ & $(42 \%)$ \\
\hline & \multirow{2}{*}{ Não } & 10 & 9 & 4 & 11 & 7 \\
\hline & & $(83 \%)$ & $(75 \%)$ & $(33 \%)$ & $(92 \%)$ & $(58 \%)$ \\
\hline & \multirow{2}{*}{ Total } & 12 & 12 & 12 & 12 & 12 \\
\hline & & $(100 \%)$ & $(100 \%)$ & $(100 \%)$ & $(100 \%)$ & $(100 \%)$ \\
\hline \multirow{6}{*}{ Curto } & \multirow{2}{*}{ Sim } & 3 & 3 & 24 & 13 & 8 \\
\hline & & $(10 \%)$ & $(10 \%)$ & $(83 \%)$ & $(45 \%)^{*}$ & $(28 \%)$ \\
\hline & \multirow{2}{*}{ Não } & 26 & 26 & 5 & 16 & 21 \\
\hline & & $(90 \%)$ & $(90 \%)$ & $(17 \%)$ & $(55 \%)$ & $(72 \%)$ \\
\hline & \multirow{2}{*}{ Total } & 29 & 29 & 29 & 29 & 29 \\
\hline & & $(100 \%)$ & $(100 \%)$ & $(100 \%)$ & $(100 \%)$ & $(100 \%)$ \\
\hline \multirow{6}{*}{$\begin{array}{l}\text { Curto e } \\
\text { anteriorizado }\end{array}$} & \multirow{2}{*}{ Sim } & 1 & 0 & 3 & 3 & 1 \\
\hline & & $(17 \%)$ & $(0 \%)$ & $(50 \%)$ & $(50 \%)$ & $(17 \%)$ \\
\hline & \multirow{2}{*}{ Não } & 5 & 6 & 3 & 3 & 5 \\
\hline & & $(83 \%)$ & $(100 \%)$ & $(50 \%)$ & $(50 \%)$ & $(83 \%)$ \\
\hline & \multirow{2}{*}{ Total } & 6 & 6 & 6 & 6 & 6 \\
\hline & & $(100 \%)$ & $(100 \%)$ & $(100 \%)$ & $(100 \%)$ & $(100 \%)$ \\
\hline p-valor * & & 0,3986 & 0,2667 & 0,19 & 0,065 & 0,5039 \\
\hline
\end{tabular}

* Teste Qui-Quadrado

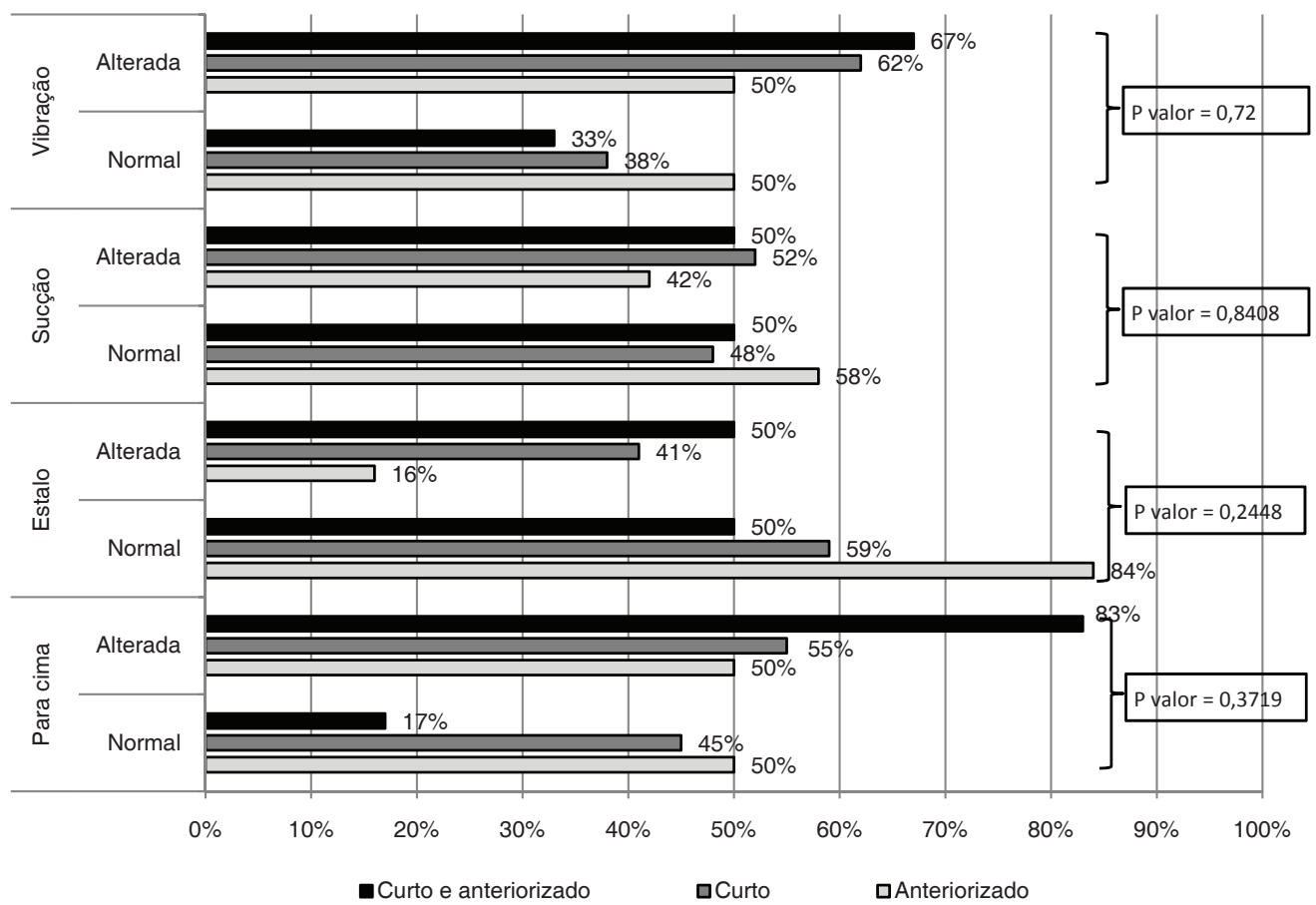

Teste Exato de Fischer

Figura 3 - Classificação do frênulo dentre as crianças com alteração de acordo com as praxias ( $\mathrm{N}=47$ ) 
Tabela 3 - Classificação do frênulo dentre as crianças com alteração de acordo com características da fala $(\mathrm{N}=47)$

\begin{tabular}{|c|c|c|c|c|c|}
\hline \multirow{2}{*}{ Características da fala } & & \multicolumn{4}{|c|}{ Classificação } \\
\hline & & Anteriorizado & Curto & $\begin{array}{c}\text { Curto e } \\
\text { anteriorizado }\end{array}$ & p-valor* \\
\hline \multirow{6}{*}{ Protrusão } & \multirow{2}{*}{ Sim } & 3 & 6 & 2 & \\
\hline & & $(25 \%)$ & $(20 \%)$ & $(33 \%)$ & \\
\hline & \multirow{2}{*}{ Não } & 9 & 23 & 4 & \\
\hline & & $(75 \%)$ & $(80 \%)$ & $(67 \%)$ & \\
\hline & \multirow{2}{*}{ Total } & 12 & 29 & 6 & \\
\hline & & $(100 \%)$ & $(100 \%)$ & $(100 \%)$ & 0,7921 \\
\hline \multirow{6}{*}{ Omissão } & \multirow{2}{*}{ Sim } & 1 & 7 & 0 & \\
\hline & & $(8 \%)$ & $(24 \%)$ & $(0 \%)$ & \\
\hline & \multirow{2}{*}{ Não } & 11 & 22 & 6 & \\
\hline & & $(92 \%)$ & $(76 \%)$ & $(100 \%)$ & \\
\hline & \multirow{2}{*}{ Total } & 12 & 29 & 6 & \\
\hline & & $(100 \%)$ & $(100 \%)$ & $(100 \%)$ & 0,2332 \\
\hline \multirow{6}{*}{ Distorção } & \multirow{2}{*}{ Sim } & 5 & 11 & 3 & \\
\hline & & $(42 \%)$ & $(38 \%)$ & $(50 \%)$ & \\
\hline & \multirow{2}{*}{ Não } & 7 & 18 & 3 & \\
\hline & & $(58 \%)$ & $(62 \%)$ & $(50 \%)$ & \\
\hline & \multirow{2}{*}{ Total } & 12 & 29 & 6 & \\
\hline & & $(100 \%)$ & $(100 \%)$ & $(100 \%)$ & 0,856 \\
\hline \multirow{6}{*}{ Articulação trancada } & \multirow{2}{*}{ Sim } & 3 & 12 & 1 & \\
\hline & & $(25 \%)$ & $(42 \%)$ & $(17 \%)$ & \\
\hline & \multirow{2}{*}{ Não } & 9 & 17 & 5 & \\
\hline & & $(75 \%)$ & $(58 \%)$ & $(83 \%)$ & \\
\hline & \multirow{2}{*}{ Total } & 12 & 29 & 6 & \\
\hline & & $(100 \%)$ & $(100 \%)$ & $(100 \%)$ & 0,3793 \\
\hline \multirow{6}{*}{ Fala rápida } & \multirow{2}{*}{ Sim } & 0 & 1 & 1 & \\
\hline & & $(0 \%)$ & (3\%) & $(17 \%)$ & \\
\hline & \multirow{2}{*}{ Não } & 12 & 28 & 5 & \\
\hline & & $(100 \%)$ & $(97 \%)$ & $(83 \%)$ & \\
\hline & \multirow{2}{*}{ Total } & 12 & 29 & 6 & \\
\hline & & $(100 \%)$ & $(100 \%)$ & $(100 \%)$ & 0,2407 \\
\hline
\end{tabular}

* Teste Qui-quadrado

No que se refere aos dados comparativos entre características de fala e alteração de frênulo, não foram encontradas diferenças significantes (Tabela 3). Em uma segunda análise, as características de fala foram agrupadas em categorias devido a pequena ocorrência para cada alteração descrita. Entretanto, esta associação também não se mostrou significante (Figura 4). Ao selecionar a amostra de indivíduos com frênulo alterado, pôde-se perceber que as alterações de fala são mais comuns em indivíduos com frênulo curto e anteriorizado. 


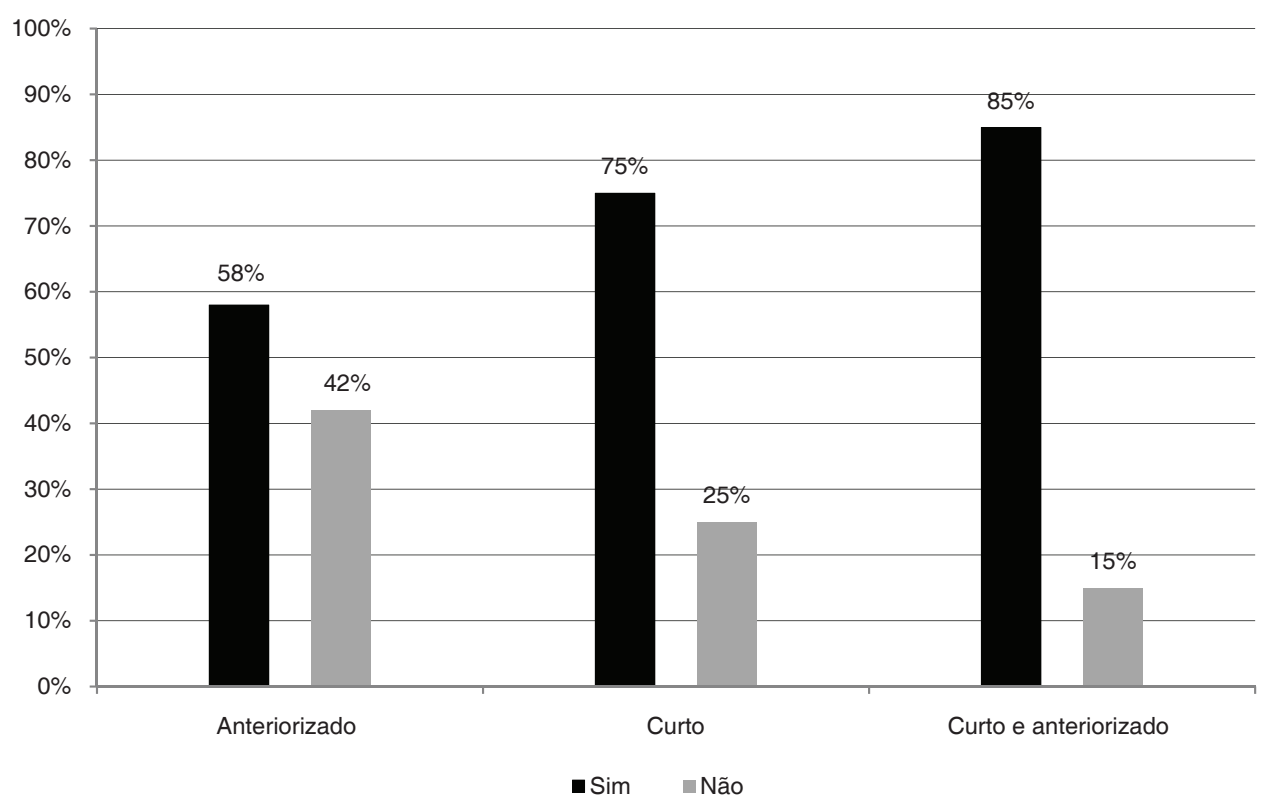

Teste Qui-Quadrado: $\mathrm{p}$-valor $=0,3865$

Figura 4 - Classificação do frênulo alterado de acordo com as implicações na fala ( $N=47)$

A Tabela 4 mostra a relação entre as características da fala com as categorias de fixação do frênulo no assoalho da boca e face lingual; esta relação não se mostrou significante. Ressalta-se que a distorção e a articulação trancada foram as características de fala mais encontradas.

$\mathrm{Na}$ Tabela 5 verificou-se a associação dos tipos de praxia mais alteradas na amostra estudada com características da fala. A categorias foram divididas em normal e alterado, sendo que indivíduos que apresentaram praxia ausente foram considerados como alterados. Não foram encontradas diferenças significantes para qualquer uma das comparações realizadas.

\section{DISCUSSÃO}

A indicação de frenectomia ou da fonoterapia visa melhor adaptação da função alterada 11,21,28. Existe considerável controvérsia entre os profissionais da saúde com relação à classificação do frênulo como normal ou alterado. A controvérsia também existe com relação à indicação ou não de cirurgia $11,13,21,28$.

Odontólogos e otorrinolaringologistas tendem a intervir cirurgicamente para corrigir as alterações do frênulo da língua ${ }^{11,21}$. O fonoaudiólogo atua avaliando as condições do frênulo da língua via inspeção visual, verificando os movimentos da língua e avaliando as funções orofaciais de mastigação, deglutição e fala. Quando necessário sugere avaliação de outro profissional, intervenção cirúrgica ou fonoterapia para correção das alterações encontradas ${ }^{6,15,17}$.

Os resultados encontrados nesta pesquisa apontaram uma amostra equivalente entre os sexos, embora a literatura mencione prevalência maior no sexo masculino ${ }^{11,12,30}$. Apenas um único estudo, realizado com 1.042 pacientes, apontou que $53,6 \%$ mulheres apresentaram mais problemas de frênulo ${ }^{15}$.

A prevalência de alterações de frênulo encontrada no estudo foi de $18 \%$. Outros achados referem prevalência de $3,49 \%{ }^{21}, 9 \%{ }^{15}, 12,8 \%{ }^{11}$ e $43,5 \%{ }^{30}$. A discrepância dos dados descritos deve-se a falta de uma definição uniforme e objetiva de um sistema de classificação para a anquiloglosssia ${ }^{5}$.

Em relação à classificação, o frênulo curto apresentou predominância sobre os demais tipos, em contraposição a outro estudo realizado por um grupo de fonoaudiólogos que apontou maior ocorrência de frênulo anteriorizado ${ }^{2}$. Com certeza isso pode ser justificado pela alta prevalência de alteração no estudo mencionado e pela questão da subjetividade, ou seja, utilização de parâmetros diferentes durante a inspeção visual.

A correlação entre os tipos de frênulo e a fixação demonstrou diferenças significantes entre os dados analisados. Na análise, considerou-se que o frênulo alterado pode estar fixado tanto na crista como na carúncula, logo o determinante para a classificação foi a face lingual. O local de fixação do frênulo na face inferior da língua, 
Tabela 4 - Fixação do frênulo dentre as crianças com alteração de acordo com características da fala $(\mathrm{N}=47)$

\begin{tabular}{|c|c|c|c|c|c|c|c|c|}
\hline \multirow{3}{*}{\multicolumn{2}{|c|}{ Características da fala }} & \multicolumn{7}{|c|}{ Fixação do frênulo } \\
\hline & & \multicolumn{3}{|c|}{ Assoalho da boca } & \multicolumn{4}{|c|}{ Face lingual } \\
\hline & & $\begin{array}{c}\text { Crista } \\
\text { alveolar }\end{array}$ & $\begin{array}{l}\text { Carúncula } \\
\text { sublingual }\end{array}$ & $\begin{array}{c}\text { p- } \\
\text { valor* }\end{array}$ & $\begin{array}{l}\text { A frente do } \\
\text { meio }\end{array}$ & $\begin{array}{c}\text { Meio da face } \\
\text { inferior }\end{array}$ & $\begin{array}{l}\text { Quase } \\
\text { ponta }\end{array}$ & $\begin{array}{c}\mathrm{p}- \\
\text { valor * }\end{array}$ \\
\hline \multirow{6}{*}{ Protrusão } & \multirow{2}{*}{ Sim } & 9 & 2 & & 2 & 5 & 4 & \\
\hline & & $(23 \%)$ & $(25 \%)$ & & $(16 \%)$ & $(20 \%)$ & $(40 \%)$ & \\
\hline & \multirow{2}{*}{ Não } & 30 & 6 & & 10 & 20 & 6 & \\
\hline & & $(77 \%)$ & $(75 \%)$ & & $(84 \%)$ & $(80 \%)$ & $(60 \%)$ & \\
\hline & \multirow{2}{*}{ Total } & 39 & 8 & & 12 & 25 & 10 & \\
\hline & & $(100 \%)$ & $(100 \%)$ & 0,9068 & $(100 \%)$ & $(100 \%)$ & $(100 \%)$ & 0,3675 \\
\hline \multirow{6}{*}{ Omissão } & \multirow{2}{*}{ Sim } & 7 & 1 & & 1 & 6 & 1 & \\
\hline & & $(18 \%)$ & $(12 \%)$ & & $(8 \%)$ & $(24 \%)$ & $(10 \%)$ & \\
\hline & \multirow{2}{*}{ Não } & 32 & 7 & & 11 & 19 & 9 & \\
\hline & & $(82 \%)$ & $(87 \%)$ & & $(92 \%)$ & $(76 \%)$ & $(90 \%)$ & \\
\hline & \multirow{2}{*}{ Total } & 39 & 8 & & 12 & 25 & 10 & \\
\hline & & $(100 \%)$ & $(100 \%)$ & 0,7087 & $(100 \%)$ & $(100 \%)$ & $(100 \%)$ & 0,6961 \\
\hline \multirow{6}{*}{ Distorção } & \multirow{2}{*}{ Sim } & 14 & 5 & & 4 & 10 & 5 & \\
\hline & & $(36 \%)$ & $(62 \%)$ & & $(34 \%)$ & $(40 \%)$ & $(50 \%)$ & \\
\hline & \multirow{2}{*}{ Não } & 25 & 3 & & 8 & 15 & 5 & \\
\hline & & $(64 \%)$ & $(37,50 \%)$ & & $(66 \%)$ & $(60 \%)$ & $(50 \%)$ & \\
\hline & \multirow{2}{*}{ Total } & 39 & 8 & & 12 & 25 & 10 & \\
\hline & & $(100 \%)$ & $(100 \%)$ & 0,1625 & $(100 \%)$ & $(100 \%)$ & $(100 \%)$ & 0,7286 \\
\hline \multirow{6}{*}{$\begin{array}{l}\text { Articulação } \\
\text { trancada }\end{array}$} & \multirow{2}{*}{ Sim } & 13 & 4 & & 4 & 10 & 3 & \\
\hline & & (33\%) & $(50 \%)$ & & (34\%) & $(40 \%)$ & $(30 \%)$ & \\
\hline & \multirow{2}{*}{ Não } & 26 & 4 & & 8 & 15 & 7 & \\
\hline & & $(67 \%)$ & $(50 \%)$ & & $(66 \%)$ & $(60 \%)$ & $(70 \%)$ & \\
\hline & \multirow{2}{*}{ Total } & 39 & 8 & & 12 & 25 & 10 & \\
\hline & & $(100 \%)$ & $(100 \%)$ & 0,3715 & $(100 \%)$ & $(100 \%)$ & $(100 \%)$ & 0,833 \\
\hline \multirow{6}{*}{ Fala rápida } & \multirow{2}{*}{ Sim } & 2 & 0 & & 1 & 0 & 0 & \\
\hline & & $(5 \%)$ & $(0 \%)$ & & $(8 \%)$ & $(0 \%)$ & $(0 \%)$ & \\
\hline & \multirow{2}{*}{ Não } & 37 & 8 & & 11 & 25 & 10 & \\
\hline & & $(95 \%)$ & $(100 \%)$ & & $(92 \%)$ & $(100 \%)$ & $(100 \%)$ & \\
\hline & \multirow{2}{*}{ Total } & 39 & 8 & & 12 & 25 & 10 & \\
\hline & & $(100 \%)$ & $(100 \%)$ & 0,5127 & $(100 \%)$ & $(100 \%)$ & $(100 \%)$ & 0,2254 \\
\hline
\end{tabular}

* Teste Qui-Quadrado

determina maior ou menor possibilidade de movimento desse músculo ${ }^{2}$. Na face lingual o frênulo curto apresentou maior número de indivíduos com a fixação no meio da face inferior da língua, o anteriorizado e o curto e anteriorizado apresentaram maior fixação quase na ponta da língua. Esses achados coincidem com o esperado, segundo a classificação utilizada ${ }^{15}$.

A tensão de língua mostrou-se reduzida na maior parte da amostra, o que corrobora estudo realizado anteriormente ${ }^{8}$. Os resultados indicaram que, semelhante a dados publicados, o posicionamento de língua não se encontra adequado na maioria dos indivíduos com alteração de frênulo ${ }^{13,19}$. A elevação do assoalho da boca foi preponderante na amostra dos indivíduos com alteração de frênulo, porém pesquisas não referem dados sobre este aspecto. Cabe ressaltar que todos os achados independem da classificação do frênulo, já que nos três tipos verificou-se as adaptações citadas. A associação entre a classificação do frênulo curto com formato da ponta de língua quadrada encontrou-se próximo ao ponto de corte, justificado pela literatura ${ }^{15}$ e frênulo curto e anteriorizado, não referido em outras pesquisas. Entretanto, outro estudo aponta maior ocorrência de língua em forma de coração ${ }^{17}$, que esteve presente em $42 \%$ das crianças com frênulo anteriorizado. 
Frênulo alterado e implicações na fala

387

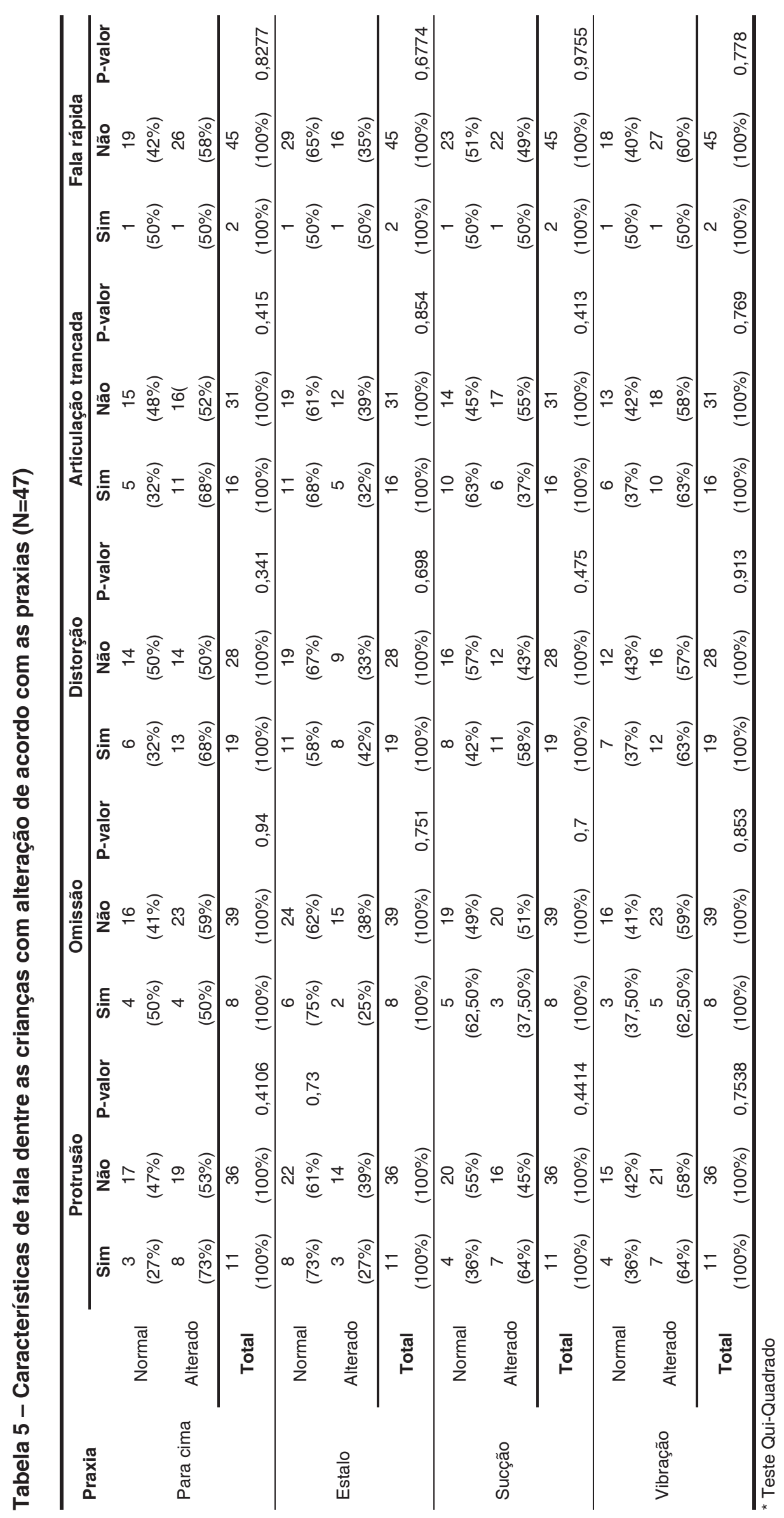

Rev CEFAC, v.11, Supl3, 378-390, 2009 
De acordo com os dados encontrados no presente estudo, as praxias que se mostraram mais alteradas foram língua para cima (83\%) e vibração $(67 \%)$ nas crianças com frênulo curto e anteriorizado e a praxia de sucção nos frênulos curtos e curto e anteriorizado. Esses dados corroboram com a literatura que afirma dificuldades de vibração da ponta de língua. Em relação à elevação da ponta da língua, $100 \%$ dos indivíduos apresentaram frênulo alterado ${ }^{23}$. Na praxia de sucção espera-se alteração nos frênulos curtos e anteriorizados, porém se observam divergências na literatura sobre os frênulos curtos. Alguns autores referenciam dificuldade de movimentos isolados de língua e/ou realização das funções ${ }^{1,27}$ e outros descrevem a não implicação do frênulo curto na mobilidade ${ }^{2,13}$.

Nos $18 \%$ dos indivíduos com alteração de frênulo, $72 \%$ apresentaram alguma alteração na fala. $\mathrm{Na}$ literatura, foi encontrado que em indivíduos com alteração de frênulo, 73,3\% apresentam fala alterada ${ }^{31}$, já outros estudos apontaram $48,8 \%{ }^{15} \mathrm{e}$ $50,0 \%{ }^{17}$. Ao considerar os tipos de alteração no frênulo e implicações na fala, tem-se que a prevalência foi maior no frênulo curto e anteriorizado (85\%), seguido pelo curto $(75 \%)$ e anteriorizado $(58 \%)$. Esses dados divergem em relação a outro estudo que observou relação maior entre alterações de fala com o frênulo anteriorizado ${ }^{31}$, já que a amostra de frênulos anteriorizados foi maior que os demais. Como a amostra deste estudo foi composta por um índice maior de frênulo curto, justifica-se o fato desse tipo de frênulo apresentar maior implicação na fala em relação ao anteriorizado.

O frênulo anteriorizado tende a limitar os movimentos da língua, sendo que quanto mais anteriormente o frênulo estiver fixado, maior será a chance de ocorrência de alteração na fala ${ }^{2,31}$. Frênulos curtos não causam no geral alterações de fala ou mesmo de mobilidade da língua. Clinicamente observa-se que línguas que têm frênulos curtos mantêm-se baixas, no assoalho da boca, o que aumenta a possibilidade de uma fala imprecisa ${ }^{15}$. Desta forma, as implicações mencionadas trazem repercussões ainda maiores em um frênulo curto e anteriorizado, já que este é associação dos dois tipos de frênulo.

Como cada tipo de frênulo apresenta características peculiares, a abordagem clínica fonoaudiológica é variável e específica para cada caso. No caso de frênulos curtos, como estes não apresentam alterações funcionais importantes, indica-se fonoterapia por dois a três meses, se esta não for efetiva, a cirurgia é indicada. Em frênulos anteriorizados, a indicação da cirurgia depende da fixação, quanto mais anteriormente fixado, maior será indicação cirúrgica, caso contrário, a fonoterapia é a conduta adotada. Nos frênulos curtos e anteriorizados a cirurgia é sempre indicada devido a implicações na fala, mobilidade, mastigação e deglutição.

Apesar da relação da fixação do frênulo da língua com as características da fala não apresentar um dado significativo, os resultados surpreenderam, pois provavelmente a fixação na face lingual pode determinar o tipo de frênulo. Logo há uma relação importante entre a fixação do frênulo e características da fala.

Ao considerar os tipos de alteração na fala, encontrou-se distorção nos fones [r], [s] e [z]; protrusão de língua no [t], [d], [l] e omissão no [r], em conformidade com estudos anteriores 8,14,16,19,22,23. Ressalta-se que a distorção prevaleceu em relação às demais características da fala. A literatura não descreve alterações na fala por categorias (protrusão, omissão, distorção), apenas aponta os fones mais alterados.

Apesar da ausência de associação estatística, algumas características de fala apresentaram maior frequência de alteração nas praxias, como a distorção, articulação trancada, protrusão e omissão. A praxia para cima foi mais comum dentre as alterações de fala descritas acima, com excessão da omissão, na qual a praxia de vibração mostrou-se mais alterada. Não foram realizadas pesquisas que referem a relação entre as praxias e alterações de fala de forma específica (protrusão, omissão, distorção, articulação trancada). Encontrou-se apenas estudos que afirmaram associação entre alteração de frênulo e limitações dos movimentos de língua ${ }^{6-9,12,23,24}$.

A distorção ocorre quando o indivíduo busca ajustes ou compensações para uma fala mais inteligível. Pode estar relacionada ao posicionamento inadequado da língua ${ }^{32}$ possivelmente determinado pela fixação do frênulo. A fixação do frênulo da língua pode repercutir na mobilidade e em realizar algumas funções estomatognáticas ${ }^{7}$. Como a fala é uma das funções estomatognáticas, pode-se dizer que há uma correlação entre a fixação do frênulo e alterações de fala, como descrito anteriormente.

A articulação trancada ${ }^{8,15,21,22}$, é uma compensação decorrente da redução da mobilidade de língua, pois na tentativa de produzir os pontos articulatórios corretamente, o falante reduz o espaço entre os maxilares durante a articulação da fala. A articulação trancada é um dos fatores de causa da imprecisão articulatória. Esta ao contrário da distorção, costuma afetar a fala como um todo ${ }^{32}$.

Supõe-se que a protusão também esteja relacionada com o posicionamento, ou seja, o sujeito adapta sua articulação, realiza movimentos mandibulares de anteriorização, interdentaliza os fonemas linguodentais, alveolares e líquidas ${ }^{19}$ e com a 
tensão de língua. Já a omissão ocorre devido à dificuldade do falante em movimentar a língua, associada à tensão de língua reduzida, o que dificulta a vibração da mesma e na execução do fone [r].

Ressalta-se que o presente estudo contribuiu para que os profissionais da saúde, possam ser mais criteriosos durante a avaliação do frênulo e assim correlacionar os dados da mesma, de forma a realizar um raciocínio clínico adequado, em conjunto com outros profissionais, viabilizando a efetividade e sucesso do tratamento.

As dificuldades encontradas para a realização do estudo, referiram-se principalmente a poucas pesquisas fonoaudiológicas publicadas envolvendo o tema, que ainda necessita ser mais difundido, pois dificultou o embasamento teórico e algumas correlações entre os dados obtidos.
Sugere-se que novos estudos sejam realizados visando associações entre as implicações na fala e alterações de frênulo com amostras mais representativas e faixas etárias diferentes para promoção de maior discussão acerca dos dados obtidos.

\section{CONCLUSÃO}

A prevalência de alteração no frênulo lingual dentre os avaliados foi de $18 \%$, sem diferença entre os sexos. O frênulo curto predominou sobre os demais tipos, porém o curto e anteriorizado apresentou maiores implicações na fala. As características de fala mais encontradas foram a distorção e a articulação trancada.

\begin{abstract}
Purpose: to check the prevalence of altered tongue frenum and its implications on the scholar's speech. Methods: tongue frenum of 260 children between 6 and 12 years old was evaluated by three speech therapists using visual inspection and caliper measurements. The children that showed changes in all stages of the evaluation were those considered to be with frenum alteration. The speech was evaluated in those children with altered tongue frenum. Results: the found data revealed that from the 260 children, $47(18 \%)$ had altered tongue frenum, being $28(60 \%)$ classified as short, $12(25 \%)$ as anterior and $7(15 \%)$ as short and anterior. There weren't differences between sexes. Modifications on speech were seen in 34 children (72\%) of those that had altered tongue frenum. The prevalence of speech alteration was higher in short and anterior frenum (85\%) followed by short $(75 \%)$ and anterior (58\%). The most founded common speech implications were distortion and locked articulation. Conclusion: a prevalence of $18 \%$ in altered tongue frenum was verified among the evaluated scholars, with no differences between genders. The short frenum is the predominant type, although the short and anterior ones are more related to altered speech. The most common speech characteristics in these cases are distortion and locked articulation.
\end{abstract}

KEYWORDS: Prevalence; Tongue; Tongue Frenum; Tongue Diseases; Speech Disorders; Speech Therapy

\section{REFERÊNCIAS}

1. Comitê de Motricidade Orofacial da Sociedade Brasileira de Fonoaudiologia. Documento oficial 04/2007. São Paulo: Sociedade Brasileira de Fonoaudiologia; 2007.

2. Marchesan IQ, Rehder MIBC, Oliveira LR, Martineli RCL, Costa MLVCMC, Araújo RLT. Interrelação do frênulo da língua e alterações de fala em crianças de 1A. a 3A. série [resumo]. Rev Soc Bras Fonoaudiol. 2008; Supl Espec.

3. Moreira M. Desenvolvimento anatomofuncional da boca da fase pré-natal aos três anos de idade. In: Correa MSNP. Odontopediatria na primeira infância. São Paulo: Santos; 1998. p.516-8.
4. Podesta MCE, Del Arco MSN, Melendez PGT, González BAC. Diagnóstico clínico de anquiloglosia, posibles complicaciones y propuesta de solución quirúrgica. Gac Odontol. 2001; 3(2):13-7.

5. Messner AH, Lalakea ML. Ankyloglossia: controversies in management. Int $\mathrm{J}$ Pediatr Otorhinolaryngol. 2000; 54(2-3):123-31.

6. Garcia-Pola MJ, Garcia-Martin JM, GonzalezGarcia M. Prevalence of oral lesions in the 6-yearold pediatric population of Oviedo (Spain). Med Oral. 2002; 7(3):184-91.

7. Cukier-Blaj S, Oliveira L, Svicero MA, Gregio F, Marchesan IQ, Camargo Z. Descrição acústica dos sons líquidos em posição de ataque e encontro consonantal em indivíduos com alteração do frênulo 
de língua [resumo]. Rev Soc Bras Fonoaudiol. 2007; Supl Espec.

8. Silva AMT, Morisso MF, Diettrich D, Weber E, Serpa E. Ocorrência de alterações do sistema estomatognático em indivíduos com anquiloglossia [resumo]. Rev Soc Bras Fonoaudiol. 2004; Supl Espec.

9. Oliveira LR, Araújo RLT, Costa MLVCM, Marchesan IQ. Análise comparativa da mastigação em pacientes com e sem alteração do frênulo lingual [resumo]. Rev Soc Bras Fonoaudiol. 2007; Supl Espec.

10. Messner AH, Lalakea ML, Aby J, Macmahon J, Bair E. Ankyloglossia: incidence and associated feeding difficulties. Arch Otolaryngol Head Neck Surg. 2000; 126(1):36-9.

11. Ballard JL, Auer CE, Khoury JC. Ankyloglossia: assessment, incidence, and effect of frenuloplasty on the breastfeeding dyad. Pediatrics. 2002; 110(5):e63.

12. Ruffoli R, Giambelluca MA, Scavuzzo MC, Bonfigli D, Cristofani R, Gabriele $M$, et al. Ankyloglossia: a morphofunctional investigation in children. Oral Dis. 2005; 11(3):170-4.

13. Marchesan IQ. Frênulo lingual: proposta de avaliação quantitativa. Rev. CEFAC. 2004; 6(3):288-93.

14. Wallace AF. Tongue-tie. Lancet. 1963; 2(7304):377-8.

15. Marchesan IQ. Frênulo de língua: classificação e interferência na fala. Rev. CEFAC. 2003; 5(4):341-5. 16. Messner $\mathrm{AH}$, Lalakea ML. The effect of ankyloglossia on speech in children. Otolaryngol Head Neck Surg. 2002; 127(6):539-45.

17. Lalakea ML, Messner AH. Ankyloglossia: the adolescent and adult perspective. Otolaryngol Head Neck Surg. 2003; 128(5):746-52.

18. Lalakea ML, Messner AH. Ankyloglossia: does it matter? Pediatr Clin North Am. 2003; 50(2):381-97. 19. Silva AMT, Morisso MF, Diettrich D, Serpa E, Weber E. Deglutição atípica e alterações fonoarticulatórias em indivíduos com anquiloglossia [resumo]. Rev Soc Bras Fonoaudiol. 2004; Supl Espec.

RECEBIDO EM: 03/03/2009

ACEITO EM: 21/09/2009

Endereço para correspondência:

Lívia Augusta dos Santos Braga

Rua Frei Mateus, 9

Belo Horizonte - MG

CEP: 30530-480

E-mail: liviabragafono@yahoo.com.br
20. Hall DMB, Renfrew MJ. Frenulo linguale corto (língua legata). Arch Dis Child. 2005; 90:1211-5.

21. Navarro NP, López M. Anquiloglosia en niños de 5 a 11 años de edad. Diagnóstico y tratamiento. Rev Cuba Estomatol. 2002; 39(3):282-301.

22. Ostapiuk B. [Tongue mobility in ankyloglossia with regard to articulation]. Ann Acad Med Stetin. 2006; 52(Suppl3):37-47.

23. Gonçalves CS, Ferreiro MC. Estudo da relação entre presença de frênulo lingual curto e/ ou anteriorizado e a dorsalização do fone [r] na articulação da fala. Rev CEFAC. 2006; 8(1):56-60.

24. Gonçalves CS. A fala da língua presa. In: Paniz IMS, Ribas LP, organizadores. Anuário de fonoaudiologia da Feevale. Novo Hamburgo: Feevale; 2004.p.61-6.

25. Dollberg S, Botzer E, Grunis E, Mimouni FB. Immediate nipple pain relief after frenotomy in breastfed infants with ankyloglossia: a randomized, prospective study. J Pediatr Surg. 2006; 41(9):1598-600.

26. Segal LM, Stephenson R, Dawes M, Feldman P. Prevalence, diagnosis, and treatment of ankyloglossia: methodologic review. Can Fam Physician. 2007; 53(6):1027-33.

27. Medeiros AMC, Medeiros M. Avaliação fonoaudiológica. In: Medeiros AMC, Medeiros M. Motricidade orofacial inter-relação entre fonoaudiologia e odontologia. São Paulo: Lovise; 2006. p. 76-98.

28. Kotlow LA. Ankyloglossia (tongue-tie): a diagnostic and treatment quandary. Quitessence Int. 1999; 30(4):259-62.

29. Perilo TVC, Motta AR, Las Casas EB, Saffar JME, Costa CG. Avaliação objetiva das forças axiais produzidas pela língua de crianças respiradoras orais. Rev Soc Bras Fonoaudiol. 2007; 12(3):184-90. 30. Marchesan IQ, Rehder MIBC, Oliveira LR, Araújo RLT, Costa MLVCMC, Martineli RCL. Incidência de alterações de frênulo da língua em uma população de crianças de $1^{\underline{a}}$ a $3^{\underline{a}}$ série do ensino fundamental [resumo]. Rev Soc Bras Fonoaldiol. 2008; Supl Espec.

31. Marchesan IQ, Rehder MIBC, Araújo RLT, Oliveira LR, Martineli RCL, Costa MLVCMC. Ocorrência de alterações de sonoridade na fala em um grupo de crianças com frênulo lingual alterado [resumo]. Rev Soc Bras Fonoaudiol. 2008; Supl Espec.

32. Marchesan IQ. Alterações de fala de origem musculoesquelética. In: Ferreira LP, Befi-Lopes DM, Limongi SCO. Tratado de fonoaudiologia. São Paulo: Roca; 2004. p. 292-303. 